\title{
Clinical and animal research findings in pycnodysostosis and gene mutations of cathepsin K from 1996 to 2011
}

\author{
Yang Xue ${ }^{1,2}$, Tao $\mathrm{Cai}^{3}$, Songtao Shi ${ }^{4}$, Weiguang Wang ${ }^{5}$, Yanli Zhang ${ }^{2}$, Tianqiu Mao ${ }^{1^{*}}$ and Xiaohong Duan ${ }^{2^{*}}$
}

\begin{abstract}
Cathepsin K (CTSK) is a member of the papain-like cysteine protease family. Mutations in the CTSK gene cause a rare autosomal recessive bone disorder called pycnodysostosis (OMIM 265800). In order to follow the advances in the research about CTSK and pycnodysostosis, we performed a literature retrospective study of 159 pycnodysostosis patients reported since 1996 and focused on the genetic characteristics of CTSK mutations and/or the clinical phenotypes of pycnodysostosis. Thirty three different CTSK mutations have been found in 59 unrelated pycnodysostosis families. Of the 59 families, 37.29\% are from Europe and 30.51\% are from Asia. A total of 69.70\% of the mutations were identified in the mature domain of CTSK, $24.24 \%$ in the proregion, and $6.06 \%$ in the preregion. The hot mutation spots are found in exons 6 and 7. CTSK mutations result in total loss or inactivity of the CTSK protein, which causes abnormal degradation of bone matrix proteins such as type I collagen. Skeletal abnormalities, including short stature, an increase in bone density with pathologic fractures, and open fontanels and sutures, are the typical phenotypes of pycnodysostosis. Research on $\mathrm{Ctsk}^{-1-}$ mouse models was also reviewed here to elucidate the biological function of Ctsk and the mechanism of pycnodysostosis. New evidence suggests that Ctsk plays an important role in the immune system and may serve as a valid therapeutic target in the future treatment of pycnodysostosis.
\end{abstract}

Keywords: cathepsin K pycnodysostosis, osteoclast, bone, oral deformities

\section{Introduction}

Pycnodysostosis (OMIM 265800) is a rare autosomal recessive bone disorder resulting from osteoclast dysfunction [1-4]. The first case of pycnodysostosis was described in 1923 by Montanari; however, Maroteaux and Lamy defined the typical features of pycnodysostosis (Greek: pycnos = dense; dys = defective; osteon = bone) in 1962. Thus, it is also known as Maroteaux-Lamy syndrome. This disorder is also called Toulouse-Lautrec syndrome after the famous French artist Henri de Toulouse-Lautrec, who was thought to be afflicted with the disease $[2,3,5]$. Less than 200 cases have been reported worldwide since 1962 [1]. The prevalence of pycnodysostosis is estimated

\footnotetext{
* Correspondence: tqmao@fmmu.edu.cn; xhduan@fmmu.edu.cn 'Department of Oral and Maxillofacial Surgery, School of Stomatology, the Fourth Military Medical University, 145 West Changle Road, Xi'an 710032, P. R. China

${ }^{2}$ Department of Oral Biology, School of Stomatology, the Fourth Military Medical University, 145 West Changle Road, Xi'an 710032, P. R. China Full list of author information is available at the end of the article
}

to be 1 to 1.7 per million with equal sex distribution [4-7]. The typical features of pycnodysostosis include short stature, an increase in the bone density of long bones, pathological fractures with poor healing, stubby hands and feet with dystrophic nails, unossified fontanels, and an obtuse mandibular angle [5,8-10].

The candidate gene for pycnodysostosis was mapped to human chromosome 1q21 by genetic linkage analysis, and was subsequently identified as coding for cathepsin $\mathrm{K}$ (CTSK, MIM\# 601105) by a positional cloning strategy in 1996 [11-13]. The CTSK gene spans approximately $12 \mathrm{~kb}$ (GenBank acc. no., NC_000001.10) and contains 8 exons (GenBank acc. no., NM_000396.2). The codon for the translation initiator methionine (Met1) is located in exon 2 , whereas the termination codon is located in exon 8 . The CTSK protein, highly similar to cathepsins $\mathrm{S}$ and $\mathrm{L}$, is a member of the papain-like cysteine protease family. Like most papain-like cysteine proteases, CTSK consists of 329 amino acids (GenBank acc. no., NP_000387.1), including a

\section{() Biomed Central}


15-amino acid preregion, a 99-amino acid proregion, and a 215 -amino acid mature active enzyme [14]. CTSK is synthesized as an inactive precursor protein and requires removal of its $\mathrm{N}$-terminal proregion for activation. This autocatalytic process occurs under a low-pH environment [3].

To date, it is difficult to find a full description of the characteristics of specific gene mutations and clinical manifestations of pycnodysostosis in the literature. In this study, we analyzed the reported CTSK mutations and summarized the typical clinical features of pycnodysostosis from 159 reported patients and some animal research findings in Ctsk gene knockout mice ( $\mathrm{Ctsk}^{-/-}$mice). Early reports of CTSK mutations were renamed in this study with the first base in the CTSK gene (GenBank acc. no., NC_000001.10) as the +1 position in genomic DNA, and the A of the ATG-translation initiation codon as nucleotide +1 in cDNA (GenBank acc. no., NM_000396.2).

\section{Structure of CTSK}

CTSK is also called lysosomal cysteine cathepsin K because it contains a cysteine in its active site and functions mainly in lysosomes [15]. Like most lysosomal cysteine proteases, CTSK is synthesized as an inactive proenzyme $[3,16]$. The preregion plays a critical role in targeting the protein to the endoplasmic reticulum and translocating the protein across the membrane [17-19]. While the proregion plays a role in protein folding and intracellular trafficking, it can also inhibit protease function until the proenzyme reaches the lysosome [20]. The proregion contains a conserved $\mathrm{N}$-glycosylation site (Asn103), which is supposed to facilitate lysosomal trafficking via the mannose 6-phosphate receptor pathway $[11,14,20]$. The proenzyme requires removal of its N-terminal proregion for activation [16]. This process has been proven to be autocatalytic in lysosomes at a $\mathrm{pH}$ of $4[3,21]$. CTSK consists of 2 domains folded together, resulting in a V-shaped configuration $[22,23]$. The catalytic triad, consisting of Cys139, His276, and Asn296 in the active sites, localizes at the bottom of the V cleft $[14,15,24,25]$.

\section{Distribution of CTSK}

CTSK is highly expressed in osteoclasts and has lower expression levels in the heart, lung, skeletal muscle, colon, ovary, and placenta $[3,5,20]$. Additionally, CTSK mRNA was detected in macrophages and bone marrowderived dendritic cells, but was barely detected in nonadherent bone marrow cells or splenic T cells [26,27].

\section{Function of CTSK In osteoclasts}

CTSK, which is critical for osteoclast-mediated bone resorption, is highly expressed in osteoclasts. In osteoclasts, CTSK is responsible for the degradation of bone matrix proteins, such as type I collagen, osteopontin, and osteonectin $[3,5,20]$. A tightly sealed resorption lacuna between the osteoclast and the bone is called an extracellular lysosome. Dissolution of the inorganic matrix and degradation of the organic matrix occur in the extracellular lysosome under low $\mathrm{pH}$ conditions $[28,29]$. In mature osteoclasts, CTSK is synthesized as an inactive proenzyme and cleaved by autoproteolysis to produce the active form of the protein. This active form is then secreted into the extracellular lysosome [30-32], where it degrades bone matrix proteins, particularly type I collagen, which constitutes $95 \%$ of the organic bone matrix $[3,5,15,20,33]$. CTSK deficiency does not affect the function of osteoclast-mediated extracellular acidification [34]. Ctsk mutations were found to impair the ability of osteoclasts to degrade collagen rather than demineralize the extracellular matrix.

On the other hand, CTSK may also act as a potential regulator of apoptosis and senescence, controlling osteoclast numbers in vivo [34]. Thus, impairment of CTSKmediated osteoclast apoptosis/senescence may also be responsible for the higher number of osteoclasts found in $\mathrm{Ctsk}^{-/-}$mice [34].

\section{In immunocytes}

A pycnodysostosis patient with normal immune status was reported in 1999 [35]. However, impaired killing activity of monocytes with normal phagocytic capacity and decreased levels of IL-1 secretion were reported in pycnodysostosis patients in an earlier study [36].

In an early animal study, abnormities of histological morphology or cellularity were found neither in the thymus nor in the levels of $\mathrm{B}$ and $\mathrm{T}$ lymphocytes in peripheral blood [37]. Fluorescence-activated cell sorter analysis showed no difference in the lymphocyte markers (CD4, CD8, CD3, B220, IgM, and IgD) between $\mathrm{Ctsk}^{-/-}$and wild-type mice. Immunophenotype analysis of the cell types in the bone marrow revealed a significant decrease in the absolute cell number of all subtypes, even though the percentage of each subtype in the entire population was unchanged [37].

Recently, Ctsk was found to function in the endosomes of dendritic cells. Pharmacological inhibition or targeted disruption of Ctsk led to defective Toll-like receptor 9 signaling in dendritic cells when stimulated with cytosine-phosphate- guanine, but not when stimulated with lipopolysaccharide or peptidoglycan. It was shown that Ctsk is indispensable for differentiation of dendritic cells, but not required for antigen uptake, processing, or presentation by dendritic cells. The same study also indicated that the ability of dendritic cells to induce T helper 17 (Th17) cells was markedly inhibited by Ctsk inactivation, which may be caused by a reduction in the expression of Th17 cell-related cytokines, such as IL-6 and IL-23, by dendritic cells. Furthermore, 
$\mathrm{Ctsk}^{-1-}$ mice were resistant to experimental autoimmune encephalomyelitis, in which Th17 cells are involved [26]. These results suggest that Ctsk plays an important role in the immune system and may serve as a valid therapeutic target in autoimmune diseases.

Nevertheless, it remains to be determined whether CTSK plays a pathogenic role in the human immune system or in autoimmune/inflammatory diseases.

\section{In other cells and tissues}

New evidence suggests that CTSK is involved in extracellular matrix remodeling in organs such as the lung, thyroid, and skin, and plays a critical role in the development and progression of cardiovascular disease [38]. Extensive destruction of elastin and collagen caused by overexpression of cathepsins $\mathrm{K}$ and $\mathrm{S}$ has been related to the damage and inflammation of arterial wall, resulting in atherogenesis [15,38-41].

\section{Variants in the CTSK gene}

Thirty three different mutations have been reported in 59 pycnodysostosis families [1,3,8,9,14,17,20,42-54] (Table 1, Figure 1A). The Arg241 in exon 6 and Ala277 located in CpG dinucleotides in exon 7 are two mutational hot spots for pycnodysostosis (Figure 1B). Various mutations have been reported in pycnodysostosis patients, including 23 missense mutations (69.70\%), 4 frame-shift mutations (12.12\%), 3 nonsense mutations (9.09\%), 2 splicing mutations $(6.06 \%)$, and 1 termination codon mutation (3.03\%) (Figure 1C). A total of $69.70 \%$ of the mutations occur in the mature domain of CTSK, $24.24 \%$ in the proregion, and $6.06 \%$ in the preregion (Figure 1D).

The reported families and characteristics of different mutations are summarized in Table 2. In addition to paternal uniparental disomy in 1 family, compound heterozygous mutations were found in 14 afflicted families (23.73\%), while homozygous mutations were found in 44 afflicted families (74.58\%). Of the 59 unrelated families, 37.29\% were from Europe while 30.51\% came from Asia.

\section{Characteristics of mutant CTSK proteins}

In order to determine CTSK expression, monocytederived macrophages were isolated from the peripheral blood of 2 siblings suffering from pycnodysostosis and their unaffected parents. Western blot revealed no detectable expression of either the proform or mature form of CTSK in either affected sibling with p.Gly79Glu and p.Lys52X. The levels of both proform and mature forms of CTSK in the father, a carrier of p.Gly79Glu, were nearly half that in normal controls, while the levels in the mother, a carrier of p.Lys52X, were more severely decreased [50]. In another study, monocytes were isolated from the peripheral blood of a patient with $\mathrm{p}$. Ala141Val and induced to differentiate into osteoclasts in vitro. As a result of the mutation, the ability of the patient-derived cells to resorb bone was significantly decreased [46].

Functional properties of CTSK mutants (p.Leu7Pro, p.Leu9Pro, p.Gly79Glu, p.Gly146Arg, p.Gln165Arg, p. Gly194Ser, p.Tyr212Cys, p.Ile249Thr, p.Asp250Gly, p. Ala277Glu, p.Ala277Val, p.Arg312Gly, p.Gly319Cys, and p.X330Trp) were examined by transient expression in COS-7 cells, 293 cells, and Pichia pastoris GS115 cells, respectively $[14,17,20,54]$. Western blot analysis revealed that the mutants affecting residues of the mature domain yielded a mature form of a nonfunctional protein, while the mutants p.Leu7Pro, p.Leu9Pro, and p.X330Trp yielded a trace amount of this protein. In order to further understand the protein consequences of these missense mutations, amino acid changes of the mutant proteins, including p.Leu7Pro, p.Leu9Pro, p.Gln165Arg, p.Gly194Ser, p.Ile249Thr, p. Asp250Gly, and p.Gly319Cys, were modeled into the three-dimensional structure of the full-length CTSK. These mutations are predicted to affect the conformation of the protein [14].

All of these methods, including isolation of monocytes from the pycnodysostosis patients and transfection in COS-7 cells, 293 cells, and P. pastoris GS115 cells, demonstrated that CTSK mutants are functionally different from the wild type.

\section{$\mathrm{Ctsk}^{-/-}$mouse models}

The murine Ctsk gene maps to chromosome 3, and its predicted amino acid sequence is highly homologous to the human protein (85\% identity; 93\% similarity) [11]. $\mathrm{Ctsk}^{-1-}$ mouse models play quite an important role in studying the nature and function of Ctsk in osteoclasts and other cells, in detecting the mechanisms of phenotypes of pycnodysostosis, and even in optimizing therapeutic strategies (including gene therapy) for the treatment of this genetic disorder [34,55]. A homozygous null mutation in the mouse Ctsk gene was first established in 1998. $\mathrm{Ctsk}^{-1-}$ mouse strains have been generated in different genetic backgrounds since then [34,37,56-58]. All $\mathrm{Ctsk}^{-1-}$ mouse strains could mimic the phenotype of human pycnodysostosis to different extents.

Generally, Ctsk deficient mice may survive and are fertile. The phenotype of $\mathrm{Ctsk}^{-/-}$mice resembles clinical characteristics of the human pycnodysostosis in several aspects, such as the presence of osteopetrosis, reduced bone marrow cellularity, and splenomegaly after 2 months of age $[37,58]$. Using radiography, micro-computed tomography, and histological analyses, $\mathrm{Ctsk}^{-1-}$ mice were shown to display an osteopetrotic phenotype with excessive trabeculation of the bone marrow space [56]. Deficiency of Ctsk affects the late stage of the osteoclastic resorption cycle. As a result, $\mathrm{Ctsk}^{-1-}$ mice are unique among the currently available osteopetrotic mouse models [56]. 
Table 1 Mutations in the CTSK gene causing pycnodysostosis

\begin{tabular}{|c|c|c|c|c|c|}
\hline $\begin{array}{l}\text { Location in DNA } \\
\text { sequence }\end{array}$ & $\begin{array}{l}\text { Genomic DNA sequence } \\
\text { variants }\end{array}$ & $\begin{array}{l}\text { Coding DNA sequence } \\
\text { variants }\end{array}$ & $\begin{array}{l}\text { Effect on amino } \\
\text { acid }\end{array}$ & $\begin{array}{l}\text { Location in protein } \\
\text { sequence }\end{array}$ & First description \\
\hline \multicolumn{6}{|l|}{ Missense } \\
\hline Exon 2 & g.1551T > C & c.20T > C & p.Leu7Pro & Pre & $\begin{array}{l}\text { Donnarumma, et al., } \\
2007\end{array}$ \\
\hline Exon 2 & g.1557T > C & c.26T $>C$ & p.Leu9Pro & Pre & Nishi, et al., 1999 \\
\hline Exon 3 & g.2128C > T & c. $136 \mathrm{C}>\mathrm{T}$ & p.Arg46Trp & Pro & Schilling, et al., 2007 \\
\hline Exon 3 & g. $2227 G>A$ & $c .235 G>A$ & p.Gly79Arg & Pro & $\begin{array}{l}\text { Fratzl-Zelman, et al., } \\
2004\end{array}$ \\
\hline Exon 3 & g.2228G > A & c. $236 \mathrm{G}>\mathrm{A}$ & p.Gly79Glu & Pro & Hou, et al., 1999 \\
\hline Exon 5 & g. $4120 \mathrm{C}>\mathrm{T}$ & c. $422 \mathrm{C}>\mathrm{T}$ & p.Ala141Val & Mature & $\begin{array}{l}\text { Chavassieux, et al., } \\
2008\end{array}$ \\
\hline Exon 5 & g.4134G > C & c. $436 G>C$ & p.Gly146Arg & Mature & Gelb, et al., 1996 \\
\hline Exon 5 & g.4192A > G & c. $494 \mathrm{~A}>\mathrm{G}$ & p.GIn165Arg & Mature & $\begin{array}{l}\text { Donnarumma, et al., } \\
2007\end{array}$ \\
\hline Exon 5 & g. $4258 \mathrm{~A}>\mathrm{C}$ & $C .560 A>C$ & p.GIn187Pro & Mature & Li, et al., 2009 \\
\hline Exon 5 & g.4278G > A & C.580G > A & p.Gly194Ser & Mature & $\begin{array}{l}\text { Donnarumma, et al., } \\
2007\end{array}$ \\
\hline Exon 6 & g.8644A > G & c. $635 \mathrm{~A}>\mathrm{G}$ & p.Tyr212Cys & Mature & Hou, et al., 1999 \\
\hline Exon 6 & g.8737 G > A & $c .728 \mathrm{G}>\mathrm{A}$ & p.Gly243Glu & Mature & Khan et al., 2010 \\
\hline Exon 6 & g. $8755 T>C$ & c.746T > C & p.lle249Thr & Mature & $\begin{array}{l}\text { Donnarumma, et al., } \\
2007\end{array}$ \\
\hline Exon 6 & g.8758A > G & c.749A > G & p.Asp250Gly & Mature & $\begin{array}{l}\text { Donnarumma, et al., } \\
2007\end{array}$ \\
\hline Exon 7 & g.9109C > T & $\mathrm{c} .830 \mathrm{C}>\mathrm{T}$ & p.Ala277Val & Mature & Gelb, et al., 1998 \\
\hline Exon 7 & g.9109C > A & C. $830 \mathrm{C}>\mathrm{A}$ & p.Ala277Glu & Mature & Hou, et al., 1999 \\
\hline Exon 7 & g.9171T > C & c. $892 \mathrm{~T}>\mathrm{C}$ & p.Trp298Arg & Mature & Nishi, et al., 1999 \\
\hline Exon 8 & g. $9186 \mathrm{G}>\mathrm{A}$ & C. $908 \mathrm{G}>\mathrm{A}$ & p.Gly303Glu & Mature & $\begin{array}{l}\text { Toral-Lopez et al., } \\
2010\end{array}$ \\
\hline Exon 8 & g.11474T > C & c.926T > C & p.Leu309Pro & Mature & $\begin{array}{l}\text { Haagerup, et al., } \\
2000\end{array}$ \\
\hline Exon 8 & g.11479G > C & $\mathrm{C} .931 \mathrm{G}>\mathrm{C}$ & p.Ala311Pro & Mature & Nishi, et al., 1999 \\
\hline Exon 8 & g. $11482 C>G$ & c.934C > G & p.Arg312Gly & Mature & Hou, et al., 1999 \\
\hline Exon 8 & g.11501G > A & c. $953 \mathrm{G}>\mathrm{A}$ & p.Cys318Tyr & Mature & Bertola et al., 2010 \\
\hline Exon 8 & g.11503G > T & c.955G > T & p.Gly319Cys & Mature & $\begin{array}{l}\text { Donnarumma, et al., } \\
2007\end{array}$ \\
\hline \multicolumn{6}{|l|}{ Nonsense } \\
\hline Exon 3 & g.2146A $>$ T & c. $154 \mathrm{~A}>\mathrm{T}$ & p.Lys52X & Pro & Hou, et al., 1999 \\
\hline Exon 5 & g. $4266 C>T$ & $\mathrm{c} .568 \mathrm{C}>\mathrm{T}$ & p.GIn190X & Mature & Hou, et al., 1999 \\
\hline Exon 6 & g.8730C > T & c. $721 \mathrm{C}>\mathrm{T}$ & p.Arg241X & Mature & Gelb, et al., 1996 \\
\hline \multicolumn{6}{|c|}{ Frameshifts (duplication) } \\
\hline Exon 2 & g.1591-1592dupGA & c.60_61dupGA & p.lle21ArgfsX29 & Pro & $\begin{array}{l}\text { Donnarumma, et al., } \\
2007\end{array}$ \\
\hline Exon 4 & g.2359dupA & c.282dupA & p.Val95SerfsX9 & Pro & $\begin{array}{l}\text { Donnarumma, et al., } \\
2007\end{array}$ \\
\hline \multicolumn{6}{|c|}{ Frameshifts (deletion) } \\
\hline Exon 3 & g.2230delG & c.238delG & p.Asp80ThrfsX2 & Pro & $\begin{array}{l}\text { Fratzl-Zelman, et al., } \\
2004\end{array}$ \\
\hline Exon 5 & g.4124delT & c.426delT & $\begin{array}{l}\text { p. } \\
\text { Phe142LeufsX19 }\end{array}$ & Mature & Fujita, et al., 2000 \\
\hline \multicolumn{6}{|l|}{ Splicing } \\
\hline Intron2 & g. $2112 G>A$ & c. $121-1 \mathrm{G}>\mathrm{A}$ & p.del41Val-81Met & Pro & $\begin{array}{l}\text { Haagerup, et al., } \\
2000\end{array}$ \\
\hline Exon 7 & g.9169G > A & c.890G > A; 785_890del & p.Gly262AlafsX70 & Mature & $\begin{array}{l}\text { Donnarumma, et al., } \\
2007\end{array}$ \\
\hline \multicolumn{6}{|l|}{ Stop codon } \\
\hline Exon 8 & g. $11538 A>G$ & C. $990 A>G$ & p.X330TrpextX19 & Mature & Gelb, et al., 1996 \\
\hline
\end{tabular}


A

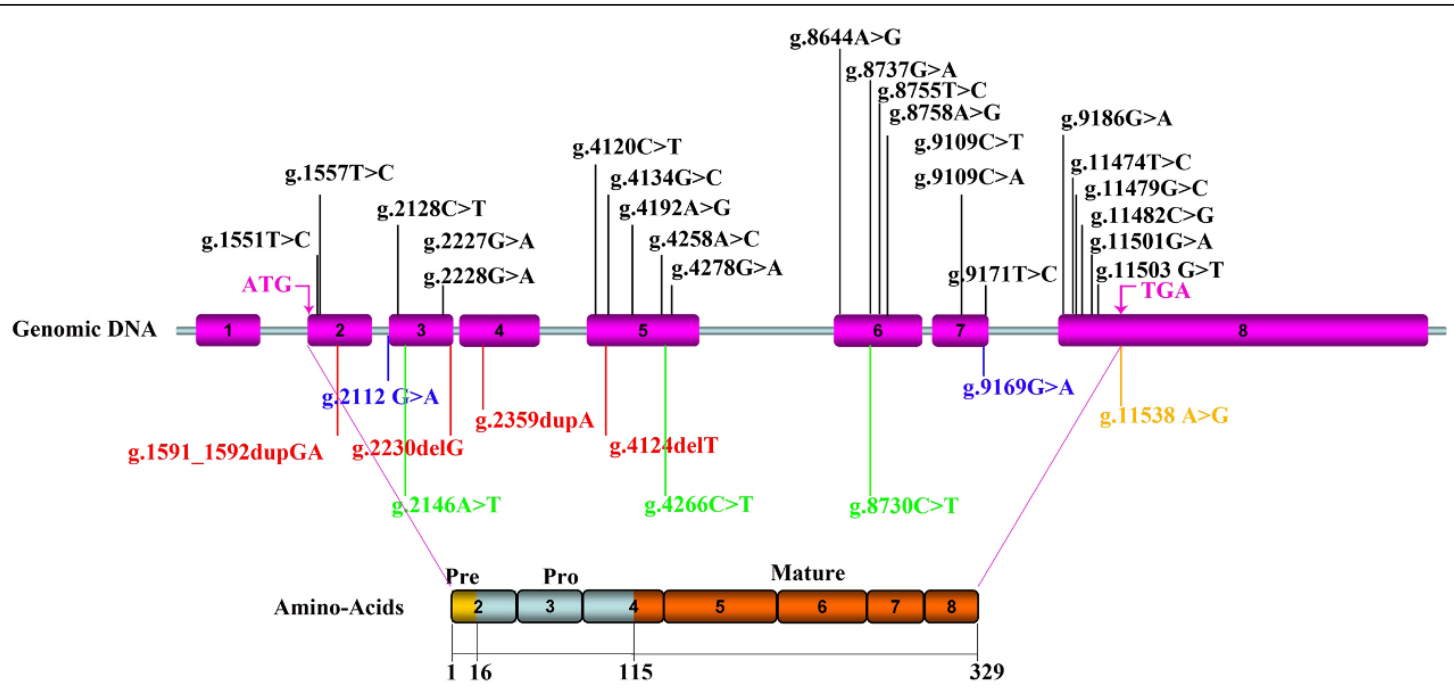

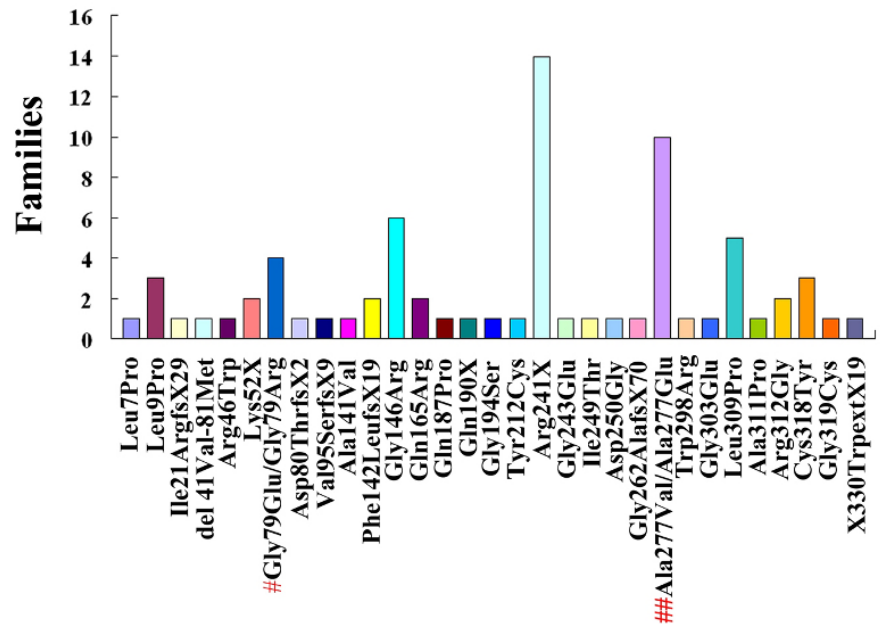

B

\section{Mutations in amino-acids}

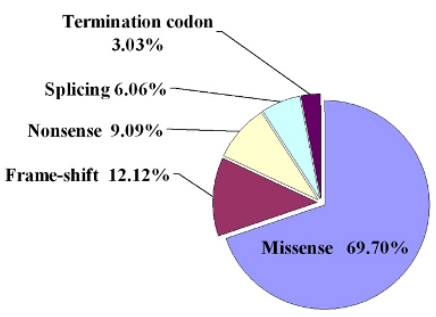

C

The type of reported mutations of $C T S K$

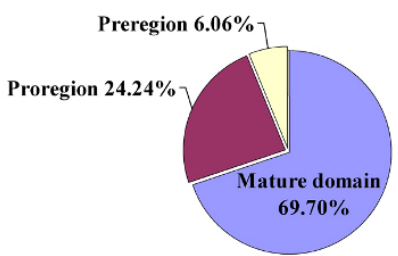

D

Distribution of reported mutations of CTSK

Figure 1 Reported mutations of CTSK. (A) Distribution of the CTSK gene and polypeptide mutations. The genomic structure of the CTSK gene with 8 exons (purple boxes numbered 1-8) is shown in the top half. The bottom half illustrates the schematic representation of the polypeptide comprising a 15-amino acid preregion (yellow box), a 99-residue proregion (light blue boxes), and a 215-amino acid mature domain (orange boxes). A total of 23 missense mutations (black type) are represented at the top of the gene diagram, while frame-shift mutations (red type), nonsense mutations (light green type), splicing mutations (blue type), and termination codon mutations (yellow type) are at the bottom. (B) Frequency of different mutations. The height of each bar represents the number of afflicted families. \#: Both mutations in the Glu70 residue. \#\#: Both mutations in the Ala277 residue. (C) The type of reported CTSK mutations. The mutations reported in pycnodysostosis patients consist of 23 missense mutations, 4 frame-shift mutations, 3 nonsense mutations, 2 splicing mutations, and 1 termination codon mutation. (D) Distribution of reported CTSK mutations. A total of $69.70 \%$ of the mutations occurred in the mature domain, $24.24 \%$ in the proregion, and $6.06 \%$ in the preregion.

$\mathrm{Ctsk}^{-1-}$ mice generally have minor craniofacial anomalies, such as increased density of the maxilla and paranasal sinus bones as well as alterations in mandibular shape [37]. Other skeletal changes seen in pycnodysostosis patient, such as growth retardation, phalangeal deformities, and delayed suture closure in the skull, have seldom been reported in $\mathrm{Ctsk}^{-1-}$ mice. Recent studies found that the pycnodysostosis phenotype in Ctsk $\mathrm{C}^{-1-}$ mice is background-dependent. Compared with other strains of $\mathrm{Ctsk}^{-/-}$mice, the phenotypical characteristics

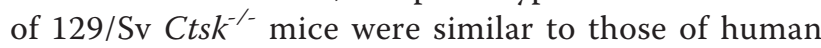
pycnodysostosis, including short stature, osteopetrosis in 
Table 2 Genotypes of pycnodysostosis patients from different nationalities

\begin{tabular}{|c|c|c|c|c|c|}
\hline Allele 1 & Allele 2 & $\begin{array}{l}\text { Patients } \\
\text { reported }\end{array}$ & $\begin{array}{l}\text { Unrelated } \\
\text { families }\end{array}$ & $\begin{array}{l}\text { Nationality of } \\
\text { patients }\end{array}$ & Reference \\
\hline C.436G > C & C. $436 \mathrm{G}>\mathrm{C}$ & 1 & 1 & Algerian & Osimani, et al., 2009 \\
\hline C. $436 \mathrm{G}>\mathrm{C}$ & c.721C > T & 1 & 1 & American Hispanic & Gelb, et al., 1996 \\
\hline c. $235 \mathrm{G}>\mathrm{A}$ & c.238delG & 1 & 1 & Austria & Fratzl-Zelman, et al., 2004 \\
\hline$c .934 C>G$ & c. $934 C>G$ & 1 & 1 & Austria & Fratzl-Zelman, et al., 2004 \\
\hline c. $830 C>T$ & $\mathrm{C} .830 \mathrm{C}>\mathrm{T}$ & 1 & 1 & Belgian & Gelb, et al., 1998 \\
\hline c. $953 \mathrm{G}>\mathrm{A}$ & c. $953 \mathrm{G}>\mathrm{A}$ & 2 & 2 & Brazil & Bertola et al., 2010 \\
\hline c. $953 \mathrm{G}>\mathrm{A}$ & c. $721 \mathrm{C}>\mathrm{T}$ & 1 & 1 & Brazil & Bertola et al., 2010 \\
\hline c. $721 \mathrm{C}>\mathrm{T}$ & C. $436 G>C$ & 1 & 1 & Brazil & Bertola et al., 2010 \\
\hline c.721C > T & c. $721 \mathrm{C}>\mathrm{T}$ & 2 & 2 & Brazil & Bertola et al., 2010 \\
\hline c. $494 A>G$ & c. $721 \mathrm{C}>\mathrm{T}$ & 1 & 1 & Caucasian & Laffranchi et al., 2010 \\
\hline c. $154 \mathrm{~A}>\mathrm{T}$ & c. $236 \mathrm{G}>\mathrm{A}$ & 2 & 1 & Caucasian & Ho, et al., 1999 \\
\hline C. $560 \mathrm{~A}>\mathrm{C}$ & C. $560 \mathrm{~A}>\mathrm{C}$ & 1 & 1 & Chinese & Li, et al., 2009 \\
\hline c. $121-1 \mathrm{G}>\mathrm{A}$ & C.926T > C & 1 & 1 & Denmark & Haagerup, et al., 2000 \\
\hline c. $236 \mathrm{G}>\mathrm{A}$ & C.926T > C & 1 & 1 & Denmark & Haagerup, et al., 2000 \\
\hline c. $926 \mathrm{~T}>\mathrm{C}$ & c.926T > C & 6 & 3 & Denmark & Haagerup, et al., 2000 \\
\hline $\begin{array}{l}\text { C.890G > A; } \\
\text { 785_890del }\end{array}$ & $\begin{array}{l}\text { C.890G > A; } \\
\text { 785_890del }\end{array}$ & 1 & 1 & Egypt & Donnarumma, et al., 2007 \\
\hline C. $136 \mathrm{C}>\mathrm{T}$ & C. $136 \mathrm{C}>\mathrm{T}$ & 3 & 1 & Germany & Schilling, et al., 2007 \\
\hline c. $934 C>G$ & C. $934 C>G$ & 2 & 1 & Honduran & Hou, et al., 1999 \\
\hline C. $.830 \mathrm{C}>\mathrm{A}$ & $\mathrm{C} .830 \mathrm{C}>\mathrm{A}$ & 1 & 1 & Indian & Hou, et al., 1999 \\
\hline C. $990 A>G$ & C. $990 \mathrm{~A}>\mathrm{G}$ & 16 & 1 & Israeli Arab & Gelb, et al., 1996 \\
\hline c.20T > C & C.580G $>\mathrm{A}$ & 1 & 1 & Italy & Donnarumma, et al., 2007 \\
\hline c. $494 A>G$ & C. $721 \mathrm{C}>\mathrm{T}$ & 1 & 1 & Italy & Donnarumma, et al., 2007 \\
\hline c. $26 \mathrm{~T}>\mathrm{C}$ & c. $26 \mathrm{~T}>\mathrm{C}$ & 2 & 2 & Japanese & Nishi, et al., 1999; Fujita, et al., 2000 \\
\hline c. $26 \mathrm{~T}>\mathrm{C}$ & $\mathrm{C} .892 \mathrm{~T}>\mathrm{C}$ & 1 & 1 & Japanese & Nishi, et al., 1999 \\
\hline c.426delT & c.426delT & 2 & 2 & Japanese & Fujita, et al., 2000 \\
\hline c. $830 \mathrm{C}>\mathrm{T}$ & $\mathrm{C} .830 \mathrm{C}>\mathrm{T}$ & 3 & 3 & Japanese & Nishi, et al., 1999; Fujita, et al., 2000 \\
\hline c. $721 \mathrm{C}>\mathrm{T}$ & C. $721 \mathrm{C}>\mathrm{T}$ & 10 & 1 & Mexican & Johnson, et al., 1996 \\
\hline c. $908 \mathrm{G}>\mathrm{A}$ & c. $908 \mathrm{G}>\mathrm{A}$ & 3 & 1 & Mexican & Toral-Lopez et al., 2010 \\
\hline c.60_61dupGA & c.60_61dupGA & 3 & 1 & Moroccan & Donnarumma, et al., 2007 \\
\hline c. $436 \mathrm{G}>\mathrm{C}$ & C. $436 G>C$ & 1 & 1 & Moroccan & Rothenbuhler et al., 2010 \\
\hline C. $436 G>C$ & C. $436 G>C$ & 2 & 1 & Moroccan Arab & Gelb, et al., 1996 \\
\hline c.282dupA & c.282dupA & 1 & 1 & Pakistan & Donnarumma, et al., 2007 \\
\hline c. $728 \mathrm{G}>\mathrm{A}$ & c.728G $>$ A & 5 & 1 & Pakistani & Khan et al., 2010 \\
\hline c.749A > G & c.749A > G & 1 & 1 & Pakistan & Donnarumma, et al., 2007 \\
\hline $\mathrm{C} .830 \mathrm{C}>\mathrm{T}$ & $\mathrm{c} .830 \mathrm{C}>\mathrm{T}$ & 5 & 3 & Pakistan & $\begin{array}{l}\text { Donnarumma, et al., 2007; Naeem, et al., } \\
2009\end{array}$ \\
\hline$c .955 G>T$ & $c .955 G>T$ & 1 & 1 & Pakistan & Donnarumma, et al., 2007 \\
\hline c. $721 \mathrm{C}>\mathrm{T}$ & c.721C > T & 2 & 2 & Portuguese & $\begin{array}{l}\text { Hou, et al., 1999; Donnarumma, et al., } \\
2007\end{array}$ \\
\hline $\mathrm{C} .830 \mathrm{C}>\mathrm{A}$ & $\mathrm{C} .830 \mathrm{C}>\mathrm{A}$ & 1 & 1 & Portuguese & Hou, et al., 1999 \\
\hline c. $635 \mathrm{~A}>\mathrm{G}$ & C. $721 \mathrm{C}>\mathrm{T}$ & 1 & 1 & Spanish & Hou, et al., 1999 \\
\hline $\mathrm{c} .721 \mathrm{C}>\mathrm{T}$ & c.746T > C & 1 & 1 & Spanish & Donnarumma, et al., 2007 \\
\hline c. $721 \mathrm{C}>\mathrm{T}$ & C. $721 \mathrm{C}>\mathrm{T}$ & 1 & 1 & Spanish & Rothenbuhler et al., 2010 \\
\hline C. $931 G>C$ & C.931G >C & 2 & 1 & Swiss & Nishi, et al., 1999 \\
\hline C. $436 G>C$ & C. $436 G>C$ & 1 & 1 & Tunisia & Donnarumma, et al., 2007 \\
\hline C. $154 \mathrm{~A}>\mathrm{T}$ & c. $236 \mathrm{G}>\mathrm{A}$ & 1 & 1 & * & Hou, et al., 1999 \\
\hline$c .568 \mathrm{C}>\mathrm{T}$ & C. $568 \mathrm{C}>\mathrm{T}$ & 1 & 1 & * & Hou, et al., 1999 \\
\hline c. $830 \mathrm{C}>\mathrm{T}$ & c. $830 \mathrm{C}>\mathrm{T}$ & 1 & 1 & * & Hou, et al., 1999 \\
\hline c. $422 \mathrm{C}>\mathrm{T}$ & c. $422 \mathrm{C}>\mathrm{T}$ & 1 & 1 & Unknown & Chavassieux, et al., 2008 \\
\hline c. $721 \mathrm{C}>\mathrm{T}$ & c. $721 \mathrm{C}>\mathrm{T}$ & 3 & 1 & Unknown & Everts, et al., 2003 \\
\hline
\end{tabular}

\footnotetext{
*: Two of the three families are from northern Europe, while the other is from Czech (no detailed record can be found in corresponding papers).
} 
the long bones, spondylolysis, acroosteolysis, bone fragility, separated cranial sutures with open fontanels, loss of the mandibular angle, lack of normal occlusion, and enhanced open bite [34].

A transgenic mouse model overexpressing the Ctsk gene showed that excess Ctsk production resulted in a high turnover of the metaphyseal trabecular bone. Enhanced bone resorption in these mice led to increased osteoblast numbers and activities, possibly mediated by core-binding protein $\alpha 1$, a transcription factor essential for osteoblast differentiation [56].

\section{Clinical relevance}

A series of typical features in clinical and radiological examinations have been observed in pycnodysostosis. We summarized the manifestations in 97 reported cases (Table 3) [1-10,17,35,42-47,50,52,53,59-91]. The most common phenotype of pycnodysostosis is short stature, which was reported in $95.9 \%$ of the 97 reported cases. The next most common phenotype is an increase in bone density, which was reported in $88.7 \%$ of the 97 patients. Open fontanels and sutures with frontal and parietal bossing, frequent fractures, hypoplasia of the maxilla and mandible with an obtuse mandibular angle, and stubby hands and feet with acroosteolysis of the distal phalanges were identified in more than $50 \%$ of the pycnodysostosis patients. Approximately one-third of the pycnodysostosis patients showed prominent eyes with bluish sclera. Additionally, these patients also show some dental defects, such as delayed eruption of permanent teeth with persistence of deciduous teeth, dental crowding, and malocclusion, which may be ignored by clinicians.

In addition to the typical manifestations mentioned above, some unusual findings, including hearing loss [5], central giant-cell granuloma of the maxilla [82], congenital pseudarthrosis of the clavicle [7], spondylolysis [79], and bone marrow hypoplasia with compensatory splenomegaly [76], were reported in pycnodysostosis patients.

Pycnodysostosis patients usually have normal life expectancies and mentations. Results of laboratory investigations, including leukocyte and thrombocyte number; mean corpuscular volume (MCV); and the levels of hemoglobin $(\mathrm{Hb})$, plasma phosphate, calcium, and alkaline phosphatase, are usually within normal limits $[1,3-5]$.

\section{Physiopathological mechanism of pycnodysostosis}

Abnormal bone metabolism is the typical physiopathological characterics of pycnodysostosis. The most common phenotype of pycnodysostosis is short stature. Based on the results of animal experiments, the short stature in pycnodysostosis may be related to the reduced size of the long bones [37].

In addition, pycnodysostosis patients usually suffer from pathologic fractures as a result of brittle, chalk-like bones. Histomorphometric and biomechanical assays in $\mathrm{Ctsk}^{-1-}$ mice have suggested that CTSK may play a critical role in matrix formation as well as breakdown. Large amounts of brittle, poorly organized matrix were formed in the absence of Ctsk gene, which corresponds to the bone fragility observed in patients with CTSK deficiency [57].

The coexistence of increased bone density in long bones (osteosclerosis) and osteolysis in the distal phalanges and calvariae is a typical characteristic of pycnodysostosis with CTSK mutation. One explanation may be the site-specific variations in bone homeostasis. It was reported that CTSK is clearly important to bone

Table 3 Typical clinical features of pycnodysostosis*

\begin{tabular}{llll}
\hline Typical features & Positive & Negative & Not mentioned \\
\hline Short stature $(<150 \mathrm{~cm})$ & $93(95.9 \%)$ & 0 & $4(4.1 \%)$ \\
Increase of bone density & $86(88.7 \%)$ & 0 & $11(11.3 \%)$ \\
Open fontanels and sutures & $68-73(70.1 \%-75.3 \%)$ & 0 & $24-29(24.7 \%-29.9 \%)$ \\
Frontal and parietal bossing & $67-72(69.1 \%-74.2 \%)$ & 0 & $25-30(25.8 \%-30.9 \%)$ \\
Fractures & $65(67.0 \%)$ & $3(3.1 \%)$ & $29(29.9 \%)$ \\
Obtuse mandibular angle & $63(64.9 \%)$ & 0 & $34(35.1 \%)$ \\
Hypoplasia of the jaws & $53-61(54.6 \%-62.9 \%)$ & 0 & $36-44(37.1 \%-45.4 \%)$ \\
Stubby hands and feet with osteolysis of the distal phalanges & $43-50(44.3 \%-51.5 \%)$ & 0 & $47-54(48.5 \%-55.7 \%)$ \\
Prominent eyes with bluish sclerae & $34(35.1 \%)$ & 0 & $63(64.9 \%)$ \\
Grooved palate & $20-28(20.6 \%-28.9 \%)$ & 0 & $69-77(71.1 \%-79.4 \%)$ \\
Dysplastic nails & $26(26.8 \%)$ & 0 & $71(73.2 \%)$ \\
Clavicular dysplasia & $24(24.7 \%)$ & 0 & $73(75.3 \%)$ \\
Nonpneumatised paranasal sinuses & $17(17.5 \%)$ & 0 & $80(82.5 \%)$ \\
Beaked nose & $16(16.5 \%)$ & 0 & $81(83.5 \%)$ \\
\hline
\end{tabular}

${ }^{*} \mathrm{n}=97$ (44 females, 42 males, and 11 unknown) 
resorption in rapidly remodeling bones (e.g., the long bones), while it is not the most essential factor in regulating the bone resorption in bones with low turnover rates, such as the calvaria and epiphysis $[34,37,48]$. On the other hand, animal experiments have shown that metalloproteinases participate in osteoclastic resorption of calvarial bones, but not of long bones [34]. The increased number of $\mathrm{Ctsk}^{-1-}$ osteoclasts may result in excessive bone resorption in the distal end of long bones (osteolysis), and the impaired ability of osteoclasts may account for the osteopetrosis in the main body of long bones $[34,37,48,56]$.

Immunophenotype analysis of the cell types in the bone marrow of $\mathrm{Ctsk}^{-1-}$ mice revealed reductions in absolute cell numbers, but not in the percentages of all the different subtypes, indicating that marrow hypoplasia results from the reduction in bone marrow cavity space, which is caused by osteopetrosis. As a result, extramedullary hematopoiesis occurs in the spleen (enlarged with a significantly elevated cellularity) to compensate for the reduced bone marrow cellularity [37].

\section{Diagnosis and differential diagnoses}

Although CTSK gene mutation analysis is the confirmatory test for pycnodysostosis, the diagnosis can be established primarily based on the aforementioned clinical features and radiograph findings [5]. On the other hand, pycnodysostosis should be distinguished from other genetic bone diseases, particularly cleidocranial dysostosis (CCD) and osteopetrosis $[5,47,68]$. Clavicular hypoplasia and typical craniofacial characteristics, especially the open fontanels and cranial sutures in pycnodysostosis, may lead to misdiagnosis of cleidocranial dysplasia. However, increased bone density with recurrent fractures is highly suggestive of pycnodysostosis [92-95]. Short stature and generalized osteosclerosis with multiple fractures in pycnodysostosis patients has been misdiagnosed as osteopetrosis [71,96-98]. However, acroosteolysis of the distal phalanges and unclosed cranial sutures and fontanels are indicative of pycnodysostosis.

\section{Treatment}

To date, no specific treatment has been validated in pycnodysostosis with the exception of symptomatic management $[5,46]$. Because bone fractures are a primary threat to these patients, it is important to prevent fracture-causing factors. These patients are likely to visit dentists because oral deformities severely affect their life. Here, we would like to emphasize the role of dentists in the diagnosis and treatment of this condition. Maintenance of oral hygiene and regular dental care may help prevent some oral complications. However, the greater bone density increases the probability of developing postextraction osteomyelitis. Thus, risk factors should be carefully addressed while planning tooth extraction and other treatments. In summary, it is quite important to establish a correct diagnosis as early as possible to prevent fractures and ensure a better quality of life $[5,6,54]$.

\section{Future prospects}

Genotype-phenotype correlation draws great attention in the field of genetic disorder research. Clinical features with CTSK genetic analysis were reported in 42 pycnodysostosis patients from 24 families [1,3,8,9,17,42-47,50,52,53]. However, the detailed clinical information was poorly described in most of the reports with molecular data. Lack of good clinical information makes it difficult to evaluate of the genotype-phenotype correlation of pycnodysostosis. More detailed information about the clinical and genetic characteristics in pycnodysostosis patients are necessary for the further research to elucidate the CTSK genotypephenotype correlation.

Research on specific approaches to correct the abnormal bone metabolism in pycnodysostosis is another hot topic. Due to providing normal osteoclasts and osteoclast-targeted enzymes, bone marrow transplantation is drawing the increasing attention. Gene replacement strategies are other alternative choices. However, considerable research is required in this area [54].

Recently, CTSK was shown to play an important role in autoimmune and inflammatory diseases by animal and in vitro experiments [26]. If the role of CTSK in the human immune system is confirmed [99], it will be helpful in further understanding of the mechanism of pycnodysostosis and in designing specific treatment strategies.

\section{List of abbreviations}

COS-7 cells: COS-7 SV40-transformed kidney cells; CTSK, Ctsk: cathepsin K; Hb: hemoglobin; IL-6: interleukin 6; IL-23: interleukin 23; MCV: mean corpuscular volume; RANKL: receptor activator of nuclear factor kappa B ligand; Th17: T helper 17 cells

\section{Acknowledgements and Funding}

This work was supported in part by grants of Key Projects of Science and Technology of Xi'an City of China [SF09027(4)], Key Projects of Science and Technology of Shaanxi Province of China (2009K17-06), and National

Scientific Foundation of China (81070819). As a disclaimer, T.C. represented his own perspective in the paper, not the NIDCR/NIH.

\section{Author details}

${ }^{1}$ Department of Oral and Maxillofacial Surgery, School of Stomatology, the Fourth Military Medical University, 145 West Changle Road, Xi'an 710032, P. R. China. ${ }^{2}$ Department of Oral Biology, School of Stomatology, the Fourth Military Medical University, 145 West Changle Road, Xi'an 710032, P. R. China. ${ }^{3}$ Oral Infection and Immunity Branch, National Institute of Dental and Craniofacial Research, National Institutes of Health, Bethesda, Maryland 20892, USA. ${ }^{4}$ Center for Craniofacial Molecular Biology, University of Southern California School of Dentistry, Los Angeles, California 90033, USA. ${ }^{5}$ Center of Cardiovascular Surgery, Xijing Hospital, the Fourth Military Medical University, 145 West Changle Road, Xi'an 710032, P. R. China. 


\section{Authors' contributions}

YX participated in reviewing papers and drafted the manuscript. TC participated in its design and helped to modify the manuscript. SS participated in its design and helped to modify the manuscript. WW participated in reviewing papers and analyzing data. YZ participated in finding papers and analyzing data. TM conceived of the study, and participated in its design and coordination and helped to modify the manuscript. XD conceived of the study, and participated in its design and coordination and helped to draft the manuscript. All authors read and approved the final manuscript

\section{Competing interests}

The authors declare that they have no competing interests.

Received: 14 February 2011 Accepted: 10 May 2011

Published: 10 May 2011

\section{References}

1. Naeem M, Sheikh S, Ahmad W: A mutation in CTSK gene in an autosomal recessive pycnodysostosis family of Pakistani origin. BMC Med Genet 2009, 10:76-80

2. Fleming KW, Barest G, Sakai O: Dental and facial bone abnormalities in pyknodysostosis: CT findings. Am J Neuroradiol 2007, 28:132-134

3. Schilling AF, Mulhausen C, Lehmann W, et al: High bone mineral density in pycnodysostotic patients with a novel mutation in the propeptide of cathepsin K. Osteoporos Int 2007, 18:659-669.

4. Soliman AT, Ramadan MA, Sherif A, et al: Pycnodysostosis: clinical, radiologic, and endocrine evaluation and linear growth after growth hormone therapy. Metabolism 2001, 50:905-911.

5. Mujawar Q, Naganoor R, Patil H, et al: Pycnodysostosis with unusual findings: a case report. Cases J 2009, 2:6544-6547.

6. Fonteles CS, Chaves CM Jr, Da Silveira A, et al: Cephalometric characteristics and dentofacial abnormalities of pycnodysostosis: report of four cases from Brazil. Oral Surg Oral Med Oral Pathol Oral Radiol Endod 2007, 104:e83-90.

7. Karakurt L, Yilmaz E, Belhan O, et al: Pycnodysostosis associated with bilateral congenital pseudarthrosis of the clavicle. Arch Orthop Trauma Surg 2003, 123:125-127.

8. Osimani S, Husson I, Passemard S, et al: Craniosynostosis: A rare complication of pycnodysostosis. Eur J Med Genet 2010, 53:89-92

9. Li HY, Ma HW, Wang HQ, et al: Molecular analysis of a novel cathepsin $\mathrm{K}$ gene mutation in a Chinese child with pycnodysostosis. J Int Med Res 2009, 37:264-269.

10. Teissier N, Jacquemont ML, Blancal JP, et al: Severe snoring in a child with pycnodysostosis treated with a bilateral rib graft. Cleft Palate Craniofac J 2009, 46:93-96

11. Gelb BD, Moissoglu K, Zhang J, et al: Cathepsin K: isolation and characterization of the murine CDNA and genomic sequence, the homologue of the human pycnodysostosis gene. Biochem Mol Med 1996, 59:200-206.

12. Polymeropoulos MH, Ortiz De Luna RI, Ide SE, et al: The gene for pycnodysostosis maps to human chromosome 1cen-q21. Nat Genet 1995, 10:238-239.

13. Gelb BD, Edelson JG, Desnick RJ: Linkage of pycnodysostosis to chromosome 1q21 by homozygosity mapping. Nat Genet 1995, 10:235-237.

14. Donnarumma M, Regis S, Tappino B, et al: Molecular analysis and characterization of nine novel CTSK mutations in twelve patients affected by pycnodysostosis. Hum Mutat 2007, 28:524-533.

15. Berdowska I: Cysteine proteases as disease markers. Clinica Chimica Acta 2004, 342:41-69.

16. LaLonde JM, Zhao $B$, Janson $C A$, et al: The crystal structure of human procathepsin K. Biochemistry 1999, 38:862-869

17. Fujita Y, Nakata K, Yasui N, et al: Novel mutations of the cathepsin K gene in patients with pycnodysostosis and their characterization. $J$ Clin Endocrinol Metab 2000, 85:425-431.

18. Schatz G, Dobberstein B: Common principles of protein translocation across membranes. Science 1996, 271:1519-1526.

19. von Heijne G: The signal peptide. J Membr Bio/ 1990, 115:195-201.
20. Hou WS, Bromme D, Zhao Y, et al: Characterization of novel cathepsin K mutations in the pro and mature polypeptide regions causing pycnodysostosis. J Clin Invest 1999, 103:731-738.

21. McQueney MS, Amegadzie BY, D'Alessio K, et al: Autocatalytic activation of human cathepsin K. J Biol Chem 1997, 272:13955-13960.

22. Li Z, Kienetz M, Cherney MM, et al: The Crystal and Molecular Structures of a Cathepsin K:Chondroitin Sulfate Complex. Journal of Molecular Biology 2008, 383:78-91.

23. Zhao Q, Jia Y, Xiao Y: Cathepsin K: A therapeutic target for bone diseases. Biochem Bioph Res Co 2009, 380:721-723.

24. Sivaraman J, Lalumiere $M$, Menard R, et al: Crystal structure of wild-type human procathepsin K. Protein Sci 1999, 8:283-290

25. Turk B, Turk V, Turk D: Structural and functional aspects of papain-like cysteine proteinases and their protein inhibitors. Biol Chem 1997, 378:141-150

26. Asagiri M, Hirai T, Kunigami T, et al: Cathepsin K-dependent toll-like receptor 9 signaling revealed in experimental arthritis. Science 2008, 319:624-627.

27. Honey K, Rudensky AY: Lysosomal cysteine proteases regulate antigen presentation. Nat Rev Immunol 2003, 3:472-482.

28. Kornak U, Kasper D, Bosl MR, et al: Loss of the CIC-7 chloride channel leads to osteopetrosis in mice and man. Cell 2001, 104:205-215.

29. Segovia-Silvestre T, Neutzsky-Wulff AV, Sorensen MG, et al: Advances in osteoclast biology resulting from the study of osteopetrotic mutations. Hum Genet 2009, 124:561-577.

30. Dodds RA, James IE, Rieman D, et al: Human osteoclast cathepsin K is processed intracellularly prior to attachment and bone resorption. $J$ Bone Miner Res 2001, 16:478-486.

31. Rieman DJ, McClung HA, Dodds RA, et al: Biosynthesis and processing of cathepsin K in cultured human osteoclasts. Bone 2001, 28:282-289.

32. Runger TM, Quintanilla-Dieck MJ, Bhawan J: Role of cathepsin K in the turnover of the dermal extracellular matrix during scar formation. $J$ Invest Dermatol 2007, 127:293-297.

33. Bromme D, Kaleta J: Thiol-dependent cathepsins: pathophysiological implications and recent advances in inhibitor design. Curr Pharm Des 2002, 8:1639-1658

34. Chen W, Yang S, Abe Y, et al: Novel pycnodysostosis mouse model uncovers cathepsin $\mathrm{K}$ function as a potential regulator of osteoclast apoptosis and senescence. Hum Mol Genet 2007, 16:410-423.

35. Alibhai ZA, Matee Ml, Chindia ML, et al: Presentation and management of chronic osteomyelitis in an African patient with pycnodysostosis. Oral Dis 1999, 5:87-89.

36. Karkabi S, Reis ND, Linn S, et al: Pyknodysostosis: imaging and laboratory observations. Calcif Tissue Int 1993, 53:170-173.

37. Gowen M, Lazner F, Dodds R, et al: Cathepsin K knockout mice develop osteopetrosis due to a deficit in matrix degradation but not demineralization. J Bone Miner Res 1999, 14:1654-1663.

38. Podgorski I: Future of anticathepsin $\mathrm{K}$ drugs: dual therapy for skeletal disease and atherosclerosis? Future Med Chem 2009, 1:21-34.

39. Lecaille F, Bromme D, Lalmanach G: Biochemical properties and regulation of cathepsin K activity. Biochimie 2008, 90:208-226.

40. Liu J, Sukhova GK, Sun JS, et al: Lysosomal cysteine proteases in atherosclerosis. Arterioscler Thromb Vasc Biol 2004, 24:1359-1366.

41. Lutgens SP, Cleutjens KB, Daemen MJ, et al: Cathepsin cysteine proteases in cardiovascular disease. FASEB J 2007, 21:3029-3041.

42. Rothenbuhler A, Piquard C, Gueorguieva I, et al: Near normalization of adult height and body proportions by growth hormone in pycnodysostosis. J Clin Endocrinol Metab 2010, 95:2827-2831.

43. Laffranchi $L$, Dalessandri $D$, Tonni I, et al: Use of CBCT in the orthodontic diagnosis of a patient with pycnodysostosis. Minerva Stomatol 2010, 59:653-661.

44. Khan B, Ahmed Z, Ahmad W: A novel missense mutation in cathepsin K (CTSK) gene in a consanguineous Pakistani family with pycnodysostosis. J Investig Med 2010, 58:720-724

45. Bertola D, Amaral C, Kim C, et al: Craniosynostosis in pycnodysostosis: broadening the spectrum of the cranial flat bone abnormalities. Am $J$ Med Genet A 2010, 152A:2599-2603.

46. Chavassieux P, Asser Karsdal M, Segovia-Silvestre T, et al: Mechanisms of the anabolic effects of teriparatide on bone: insight from the treatment of a patient with pycnodysostosis. J Bone Miner Res 2008, 23:1076-1083. 
47. Fratzl-Zelman $N$, Valenta $A$, Roschger $P$, et al: Decreased bone turnover and deterioration of bone structure in two cases of pycnodysostosis. J Clin Endocrinol Metab 2004, 89:1538-1547.

48. Everts V, Hou WS, Rialland $X$, et al: Cathepsin K deficiency in pycnodysostosis results in accumulation of non-digested phagocytosed collagen in fibroblasts. Calcif Tissue Int 2003, 73:380-386.

49. Haagerup A, Hertz JM, Christensen MF, et al: Cathepsin K gene mutations and 1q21 haplotypes in at patients with pycnodysostosis in an outbred population. Eur J Hum Genet 2000, 8:431-436.

50. Ho N, Punturieri A, Wilkin D, et al: Mutations of CTSK result in pycnodysostosis via a reduction in cathepsin $\mathrm{K}$ protein. J Bone Miner Res 1999, 14:1649-1653.

51. Nishi $Y$, Atley $L$, Eyre DE, et al: Determination of bone markers in pycnodysostosis: effects of cathepsin K deficiency on bone matrix degradation. J Bone Miner Res 1999, 14:1902-1908.

52. Gelb BD, Willner JP, Dunn TM, et al: Paternal uniparental disomy for chromosome 1 revealed by molecular analysis of a patient with pycnodysostosis. Am J Hum Genet 1998, 62:848-854.

53. Johnson MR, Polymeropoulos $M H$, Vos $H \mathrm{~L}$, et al: $\mathrm{A}$ nonsense mutation in the cathepsin $\mathrm{K}$ gene observed in a family with pycnodysostosis. Genome Res 1996, 6:1050-1055.

54. Gelb BD, Shi GP, Chapman HA, et al: Pycnodysostosis, a lysosomal disease caused by cathepsin K deficiency. Science 1996, 273:1236-1238.

55. Lazner F, Gowen M, Kola I: An animal model for pycnodysostosis: the role of cathepsin K in bone remodelling. Mol Med Today 1999, 5:413-414.

56. Kiviranta R, Morko J, Alatalo SL, et al: Impaired bone resorption in cathepsin K-deficient mice is partially compensated for by enhanced osteoclastogenesis and increased expression of other proteases via an increased RANKL/OPG ratio. Bone 2005, 36:159-172.

57. Li CY, Jepsen KJ, Majeska RJ, et al: Mice lacking cathepsin K maintain bone remodeling but develop bone fragility despite high bone mass. J Bone Miner Res 2006, 21:865-875.

58. Saftig $P$, Hunziker $E$, Wehmeyer $O$, et al: Impaired osteoclastic bone resorption leads to osteopetrosis in cathepsin-K-deficient mice. Proc Natl Acad Sci USA 1998, 95:13453-13458.

59. Yates CJ, Bartlett MJ, Ebeling PR: An atypical subtrochanteric femoral fracture from pycnodysostosis - a lesson from nature. J Bone Miner Res.

60. Toral-Lopez J, Gonzalez-Huerta LM, Sosa B, et al: Familial Pycnodysostosis: Identification of a Novel Mutation in the CTSK Gene (Cathepsin K). J Investig Med 2011, 59:277-280.

61. Hernandez-Alfaro F, Arenaz Bua J, Serra Serrat M, et al: Orthognathic surgery in pycnodysostosis: a case report. Int J Oral Maxillofac Surg 2011 40:110-113.

62. Frota R, Linard RA, de Oliveira e Silva ED, et al: Mandibular osteomyelitis and fracture in a patient with pyknodysostosis. J Craniofac Surg 2010, 21:787-789.

63. Senel S, Karacan C, Orun UA, et al: Mitral valve prolapse in two siblings with pyknodysostosis. Genet Couns 2009, 20:397-401.

64. Nagura I, Fujioka $H$, Nabeshima $Y$, et al: Monteggia fracture managed by intramedullary Kirschner wire fixation with pyknodysostosis. J Orthop Sci 2009, 14:820-822.

65. Ornetti $P$, Prati $C$, Fery-Blanco $C$, et al: Pedicle stress fracture: an unusual complication of pycnodysostosis. Clin Rheumatol 2008, 27:385-387.

66. Olubaniyi BO, Sinha AK, Bako K, et al: Extradural haematoma: a rare, but fatal complication of pyknodysostosis. Br J Neurosurg 2008, 22:594-595.

67. Soares LF, Souza IPR, Cardoso AS, et al: Pyknodysostosis: Oral findings and differential diagnosis. J Indian Soc Pedod Prevent Dent 2008, Suppl:23-25.

68. Alves Pereira D, Berini Aytes L, Gay Escoda C, Pycnodysostosis: A report of 3 clinical cases. Med Oral Patol Oral Cir Bucal 2008, 13:E633-635.

69. Ainola $M$, Valleala $H$, Nykanen $P$, et al: Erosive arthritis in a patient with pycnodysostosis: an experiment of nature. Arthritis Rheum 2008, 58:3394-3401.

70. Nakase T, Yasui N, Hiroshima K, et al: Surgical outcomes after treatment of fractures in femur and tibia in pycnodysostosis. Arch Orthop Trauma Surg 2007, 127:161-165

71. Dimitrakopoulos I, Magopoulos C, Katopodi T: Mandibular Osteomyelitis in a Patient With Pyknodysostosis: A Case Report of a 50-Year Misdiagnosis. J Oral Maxillofac Surg 2007, 65:580-585.

72. Wadia F, Shah N, Porter M: Bilateral charnley low-friction arthroplasty with cement in a patient with pyknodysostosis. A case report. J Bone Joint Surg Am 2006, 88:1846-1848.
73. Moniz N, Queiroz EA, Freitas RR, et al: Mandibular reconstruction with autogenous graft in patient presenting pyknodysostosis: case report. J Oral Maxillofac Surg 2006, 64:1292-1295.

74. Muto T, Yamazaki A, Takeda S, et al: Pharyngeal narrowing as a common feature in pycnodysostosis-a cephalometric study. Int J Oral Maxillofac Surg 2005, 34:680-685.

75. Kato H, Matsuoka K, Kato N, et al: Mandibular osteomyelitis and fracture successfully treated with vascularised iliac bone graft in a patient with pycnodysostosis. Br J Plast Surg 2005, 58:263-266.

76. Singh AR, Kaur A, Anand NK, et al: Pyknodysostosis: visceral manifestations and simian crease. Indian J Pediatr 2004, 71:453-455.

77. Norholt SE, Bjerregaard J, Mosekilde L: Maxillary distraction osteogenesis in a patient with pycnodysostosis: a case report. J Oral Maxillofac Surg 2004, 62:1037-1040.

78. Kundu ZS, Marya KM, Devgan A, et al: Subtrochanteric fracture managed by intramedullary nail in a patient with pycnodysostosis. Joint Bone Spine 2004, 71:154-156.

79. Zenke MS, Hatori M, Tago S, et al: Pycnodysostosis associated with spondylolysis. Arch Orthop Trauma Surg 2002, 122:248-250.

80. Ram PB, Ram SK, Neitzschman H: Radiology case of the month. Sclerotic bone disease in an 8-year-old dwarf. Pycnodysostosis. J La State Med Soc 2002, 154:287-288.

81. Kirita T, Sugiura T, Horiuchi $K$, et al: Mandibular reconstruction using a vascularised fibula osteocutaneous flap in a patient with pyknodysostosis. Br J Plast Surg 2001, 54:712-714.

82. Thomas N, Seshadri MS, Thomas G, et al: Association of central giant-cell granuloma of the maxilla with pyknodysostosis. Br J Oral Maxillofac Surg 2000, 38:159-160.

83. Landa S, Esteban S, Montes E, et al: Maxillofacial alterations in a family with pycnodysostosis. Med Oral 2000, 5:169-176.

84. Bathi RJ, Masur VN: Pyknodysostosis-a report of two cases with a brief review of the literature. Int J Oral Maxillofac Surg 2000, 29:439-442.

85. Agarwal I, Kirubakaran C, Sridhar G: Pyknodysostosis: a report of two siblings with unusual manifestations. Ann Trop Paediatr 1999, 19:301-305

86. O'Connell AC, Brennan MT, Francomano CA: Pycnodysostosis: orofacial manifestations in two pediatric patients. Pediatr Dent 1998, 20:204-207.

87. Hunt NP, Cunningham SJ, Adnan N, et al: The dental, craniofacial, and biochemical features of pyknodysostosis: a report of three new cases. $J$ Oral Maxillofac Surg 1998, 56:497-504.

88. Mocan H, Soylu H, Mocan MZ, et al: Pyknodysostosis: hemangioma of the skull as a new finding. Genet Couns 1997, 8:213-216.

89. Soliman AT, Rajab A, AlSalmi l, et al: Defective growth hormone secretion in children with pycnodysostosis and improved linear growth after growth hormone treatment. Arch Dis Child 1996, 75:242-244.

90. Schmitz JP, Gassmann CJ, Bauer AM, et al: Mandibular reconstruction in a patient with pyknodysostosis. J Oral Maxillofac Surg 1996, 54:513-517.

91. Darcan S, Akisu M, Taneli B, et al: A case of pycnodysostosis with growth hormone deficiency. Clin Genet 1996, 50:422-425.

92. Farronato $G$, Maspero C, Farronato D, et al: Orthodontic treatment in a patient with cleidocranial dysostosis. Angle Orthod 2009, 79:178-185.

93. Lossdorfer S, Abou Jamra B, Rath-Deschner B, et al: The role of periodontal ligament cells in delayed tooth eruption in patients with cleidocranial dysostosis. J Orofac Orthop 2009, 70:495-510.

94. Manjunath K, Kavitha B, Saraswathi TR, et al: Cementum analysis in cleidocranial dysostosis. Indian J Dent Res 2008, 19:253-256.

95. Vakili $R$, Jalali F: Hypogonadotropic hypogonadism associated with cleidocranial dysostosis. J Pediatr Endocrinol Metab 2005, 18:917-919.

96. Benichou OD, Laredo JD, de Vernejoul MC: Type II autosomal dominant osteopetrosis (Albers-Schonberg disease): clinical and radiological manifestations in 42 patients. Bone 2000, 26:87-93.

97. Del Fattore A, Cappariello A, Teti A: Genetics, pathogenesis and complications of osteopetrosis. Bone 2008, 42:19-29.

98. Tolar J, Teitelbaum SL, Orchard PJ: Osteopetrosis. N Engl J Med 2004, 351:2839-2849

99. Krieg AM, Lipford GB, Immunology: The toll of cathepsin K deficiency. Science 2008, 319:576-577.

doi:10.1186/1750-1172-6-20

Cite this article as: Xue et al: Clinical and animal research findings in pycnodysostosis and gene mutations of cathepsin K from 1996 to 2011. Orphanet Journal of Rare Diseases 2011 6:20. 